\title{
Effect of pentoxifylline on preventing acute kidney injury after cardiac surgery by measuring urinary neutrophil gelatinase - associated lipocalin
}

\author{
Khosro Barkhordari ${ }^{1 *}$, Abbasali Karimi ${ }^{2}$, Akbar Shafiee $^{3}$, Hasan Soltaninia ${ }^{1}$, Mohammad Reza Khatami ${ }^{4}$,
} Kiomars Abbasi ${ }^{2}$, Fardin Yousefshahi ${ }^{1}$, Babak Haghighat ${ }^{1}$, Virginia Brown ${ }^{5}$

\begin{abstract}
Background: Based on Acute Kidney Injury Network (AKIN) criteria, we considered acute kidney injury (AKI) as an absolute increase in the serum creatinine ( $\mathrm{s} C \mathrm{r}$ ) level of more than or equal to $0.3 \mathrm{mg} / \mathrm{dl}$ or $50 \%$. The introduction of Urinary neutrophil gelatinase-associated lipocalin (UNGAL) has conferred earlier diagnosis of AKI. Pentoxifylline (PTX), a non-specific phosphodiesterase inhibitor, can suppress the production of some factors of inflammatory response and presumably prevent AKI. We examined the PTX on the development of AKI in cardiac surgery patients by measuring the levels of UNGAL.
\end{abstract}

Materials and methods: We performed a double blind randomized clinical trial, enrolling 28 consecutive patients undergoing elective coronary artery bypass graft (CABG) surgery. Patients were divided into two groups, one to receive PTX $5 \mathrm{mg} / \mathrm{kg}$ intravenous bolus injection, followed by $1.5 \mathrm{mg} / \mathrm{kg} / \mathrm{h}$ continuous intravenous infusion until 3 hours after cessation of CPB and the other group received placebo. UNGAL was measured before, 3 and 24 hours after surgery. In addition serum creatinine was measured before and 24, 48, 72 and 96 hours after surgery and C-reactive protein (CRP) only 24 hours postoperatively.

Results: Both groups did not differ in demographic and baseline characteristics. 12 patients developed AKI 48 hours after surgery; 5 of them were in the intervention group and 7 in the control group $(p=0.445)$. There was an increase of UNGAL in both groups postoperatively, although not significant. Mean sCr was significantly increased in the control group at 24 and 48 hours after surgery (24-h mean: $0.79 \pm 0.18 \mathrm{mg} / \mathrm{dl}$ vs. $1.03 \pm 0.43 \mathrm{mg} / \mathrm{dl}, P$ value $=$ 0.02; 48-h mean: $1.17 \pm 0.24 \mathrm{mg} / \mathrm{dl}$ vs. $0.98 \pm 0.20 \mathrm{mg} / \mathrm{dl}, P$ value $=0.03$, respectively). PTX had a positive effect in preventing AKI reflecting in changes in $\mathrm{s} C r$, and the increase of UNGAL was consistent with the emergence of AKI (Pearson's correlation $=0.30$ ).

Conclusion: Our study demonstrates a weak correlation between UNGAL and $\mathrm{s} C r$ after cardiac surgery. The rise of UNGAL in these patients may be reduced by administration of PTX although we did not show significance. PTX could reduce the occurrence of AKI as determined by attenuation of $\mathrm{s} C \mathrm{r}$ rise without causing hemodynamic instability or increased bleeding. Overall, we suggest future studies with larger sample sizes to elucidate this effect and determine the different aspects of administrating PTX.

Trial Registration: ISRCTN: IRCT138807302622N1

\footnotetext{
* Correspondence: kbarkhordari@sina.tums.ac.ir

'Department of Anesthesiology and Critical Care, Tehran Heart Center,

Tehran University of Medical Sciences, Tehran, Iran

Full list of author information is available at the end of the article
} 


\section{Introduction}

Acute kidney injury (AKI) is defined by the Acute kidney injury network (AKIN) as an increase in serum creatinine level $(\mathrm{sCr})$ by more than $50 \%$ or $0.3 \mathrm{mg} / \mathrm{dL}$ or reduction of urine output to less than $0.5 \mathrm{ml} / \mathrm{kg}$ per hour [1]. AKI is a common and serious post operative complication and may occur in up to $50 \%$ of all patients undergoing cardiac surgery [2]. AKI is associated with $8 \%$ mortality rate compared with $0.9 \%$ in non-affected patients and remains a major factor for adverse outcomes [3].

Early measures to prevent postoperative AKI can help decreasing morbidity and mortality in these patients. Serum creatinine concentration and creatinine clearance are delayed and relatively insensitive markers of AKI. More sensitive and rapid markers of renal injury are more helpful for early diagnosis and treatment. Urinary neutrophil gelatinase-associated lipocalin (NGAL), with a molecular weight of $25 \mathrm{kD}$, is a novel biomarker that increases a few hours after a nephrotoxic or ischemic condition [3]. It has been observed that UNGAL level 2 hours after pediatric cardiac surgery can predict AKI with $100 \%$ sensitivity and $98 \%$ specificity [4].

Cardiopulmonary bypass (CPB) causes systemic inflammatory response syndrome (SIRS). Pentoxifylline (PTX), a non-specific phosphodiesterase inhibitor, inhibits some pro-inflammatory cytokines such as tumor necrosis factor (TNF)- $\alpha$, interleukin -10 [5] and IL-1 [6].

Xanthine Oxidase $(\mathrm{XO})$ is source of free oxygen radicals in the ischemic reperfusion injury. PTX also inhibits $\mathrm{XO}$ activity [7]. It can also affect the microcirculatory blood flow and contribute to the attenuation of interstitial inflammation, down regulation of monocyte chemoattractant protein-1 gene expression, reduction in the expression of mitogenic and profibrogenic genes, and suppression of the proliferation of interstitial fibroblast and glomerulomesangial cells [8]. However, the preclinical data with regard to PTX and AKI seems controversial $[9,10]$. The effect of PTX in reducing renal injury by measuring $\mathrm{sCr}$ and $\alpha-1$-microglobulin was investigated and ameasuring $\mathrm{sCr}$ and beneficial role of PTX on the prevention of kidney injury was observed [11]. Our study aims to investigate the effect of PTX on preventing AKI after coronary artery bypass graft (CABG) surgery, by comparing pre- and postoperative levels of NGAL and serum creatinine.

\section{Material and methods}

After informed consent, 28 consecutive adult patients undergoing elective on-pump CABG were enrolled in doubled blind randomized control trial at Tehran Heart Center from January to June 2010. The study protocol was reviewed and approved by the Research Board the
Ethics Committee at Tehran Heart Center and study funded by Tehran Heart Center. Exclusion criteria included refusal to sign the consent, Collagen-vascular disease, use of immunosuppressive agents, corticosteroids ( $>3$ days), methylxantines, diltiazem or sodium nitroprusside, angiography in the past 7 days, hemorrhagic diathesis and coagulopathy, uncontrolled diabetes mellitus, sepsis, renal failure $(\mathrm{sCr}>2 \mathrm{mg} / \mathrm{dl})$, hepatic failure (AST or ALT > $40 \mathrm{U} / \mathrm{L}$ ) or urinary tract infection. The patients were randomly assigned to one of two groups: (A) the control group (placebo), and (B) the intervention group (PTX). All patients received the same anesthetic regimen and routine $\mathrm{CPB}$ management. Anesthesia was induced by midazolam $(0.05 \mathrm{mg} / \mathrm{kg})$, fentanyl $(5 \mathrm{mcg} / \mathrm{kg}$ ), propofol $2 \mathrm{mg} / \mathrm{kg}$ and pancoronium $(0.1 \mathrm{mg} / \mathrm{kg})$, and was maintained with propofol infusion $(10 \mathrm{mg} / \mathrm{kg} / \mathrm{h})$ and additional doses of fentanyl and pancoronium. After induction of anesthesia, PTX (Aventis, Switzerland) was administered as an intravenous (IV) bolus dose of $5 \mathrm{mg} / \mathrm{kg}$ over 5 minutes, followed by 1.5 $\mathrm{mg} / \mathrm{kg} / \mathrm{h}$ slow IV infusion up to 3 hours after cessation of CPB pump. In the control group, normal saline was used as placebo. UNGAL was measured by ELISA method after induction of anesthesia and repeated at 3 and 24 hours postoperatively. Danish Bioporto ${ }^{\circledR}$ rapid ELISA kits were utilized to measure UNGAL. SCr levels were measured before, 24, 48, 72 and 96 hours after surgery and C-reactive protein (CRP) checked before and 24 hours postoperatively. AKI was considered as $50 \%$ or $0.3 \mathrm{mg} / \mathrm{dl}$ increase in $\mathrm{sCr}$ level following surgery. Demographic characteristics, Euroscore, concurrent risk factors, infused serum volume and the time of intubation were recorded for each patient

\section{Statistical analysis}

The results are presented as mean \pm standard deviation (SD) for the quantitative variables and are summarized by absolute frequencies and percentages for categorical variables. The continuous variables were compared using Student's $t$-test or nonparametric Mann-Whitney $U$ test in not normally distributed data, categorical variables were compared using Fisher's exact test since more than $20 \%$ of cells with expected count of less than 5 were observed. Normal distribution of data was evaluated by Kolmogorov-Smirnov test. Pearson's correlation coefficient was also conducted to assess the Linearity degree between the quantitative measurements. The differences between the two groups were evaluated by the two-way repeated-measures analysis of variance (ANOVA) across the all time measurements. In each ANOVA model, time was treated as a within subject factor and group and the interaction term between group and time (Group*Time) also included in the model. 
For the statistical analysis, the statistical software SPSS version 13.0 for windows (SPSS Inc., Chicago, IL) was used. P values of 0.05 or less were considered statistically significant.

\section{Results}

Half of the 28 patients undergoing CABG and met the criteria were randomized to receive PTX. Both groups were similar in demographic and pre and intraoperative characteristics. Inotropic and vasopressor drugs were used similarly in both groups during and after surgery; there was no significant difference in their doses and frequency of administration (Table 1). Number of bypass grafts in the intervention group was $3.14 \pm 1.17$ compared to $3.36 \pm 1.75$ in the control group which was not different $(p=0.56)$.

A measurement of UNGAL 3 hours after surgery showed an increase in both groups, but the difference between the groups was not significant $(p=0.294)$. Twenty four hours after surgery, the difference in rising UNGAL levels between the two groups remained insignificant $(p=0.587)$ (Figure 1$)$. While comparing ANOVA models, the interaction terms did not reach the significant level in both models ( $p=0.467$ for Creatinine and $p=0.759$ for NGAL).

AKI developed overall in 2 (7\%) (1 in the intervention group vs. 1 in the control group) and $12(42 \%)$ of patients $(5(35 \%)$ in the intervention group vs. $7(50 \%)$ in the control group) 24 and 48 hours after surgery, respectively $(p=0.445)$.

There was a significant difference regarding mean $\mathrm{sCr}$ levels 24 and 48 hours postoperatively ( $p=0.02$ and $p=$ 0.03 , respectively). The level of $\mathrm{sCr}$ in 72 and 96 hours was not different between the groups. ( $p=0.12$ and $p=$ 0.69 , respectively) (Figure 2).

Table 1 Demographic and baseline data of the patients

\begin{tabular}{llll}
\hline Variable & $\begin{array}{l}\text { Intervention } \\
(\mathbf{n}=\mathbf{1 4})\end{array}$ & $\begin{array}{l}\text { Control } \\
(\mathbf{n}=\mathbf{1 4})\end{array}$ & P-value* \\
\hline Male gender $(\mathrm{n})$ & $10(71.4 \%)$ & $13(92.9 \%)$ & 0.32 \\
\hline Age (year) & $58.86 \pm 9.41$ & $57.14 \pm 11.43$ & 0.66 \\
\hline Weight (kg) & $77.71 \pm 10.02$ & $82.17 \pm 12.59$ & 0.31 \\
\hline Euroscore (Standard score) & $1.86 \pm 2.07$ & $2.14 \pm 1.79$ & 0.69 \\
\hline LVEF' (\%) & $50.00 \pm 6.79$ & $49.23 \pm 7.31$ & 0.79 \\
\hline Mean ABP ${ }^{2}(\mathrm{~mm} H g)$ & $60.43 \pm 15.32$ & $64.86 \pm 8.82$ & 0.35 \\
\hline CVP (cm $\left.\mathrm{H}_{2} \mathrm{O}\right)$ & $9.00 \pm 3.08$ & $7.50 \pm 2.82$ & 0.19 \\
\hline Baseline sCr level (mg/dl) & $0.81 \pm 0.15$ & $0.78 \pm 0.18$ & 0.56 \\
\hline Baseline UNGAL level (ng/ml) & $10.36 \pm 8.61$ & $10.57 \pm 3.54$ & 0.93 \\
\hline Baseline CRP level & $0.21 \pm 0.12$ & $0.32 \pm 0.27$ & 0.20 \\
\hline * P values <0.05 were considered as significant. & & \\
1. Left Ventricular Ejection Fraction. & & \\
2. Arterial Blood Pressure. & & & \\
3. Central Venous Pressure. & & & \\
\hline
\end{tabular}

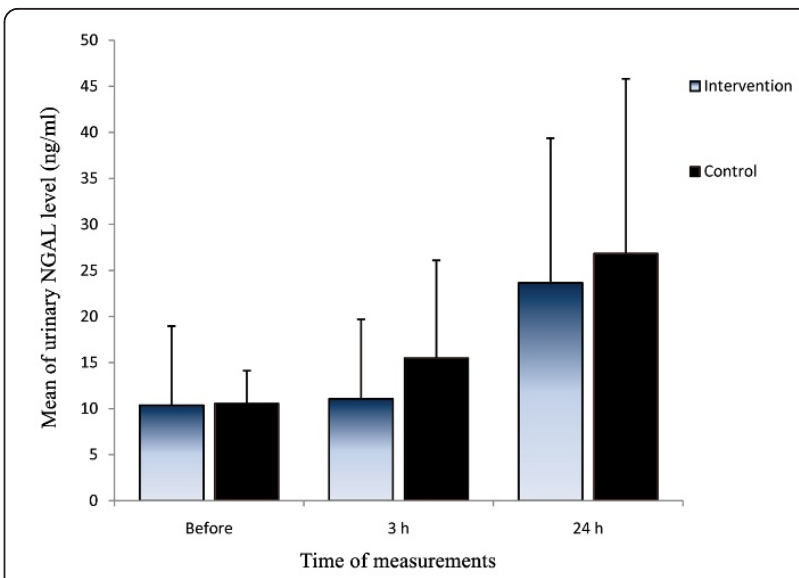

Figure 1 Comparing UNGAL level before and after CABG between the intervention group and the controls (Median/ interquartile range).

Overall, the increase in UNGAL was slightly correlated with the emergence of $\mathrm{AKI}$ as detected by $\mathrm{sCr}$ levels (Pearson's correlation coefficient $r=0.30$ ). Also, there was no significant difference in $24 \mathrm{~h}$ postoperative CRP levels $(p=0.56)$ between the groups. Intubation time was also indifferent $(p=0.28)$. Common side effects of PTX (i.e., bleeding, nausea and vomiting) were not significantly higher in the intervention group than those of the control group (Table 2).

\section{Discussion}

Our study aimed to investigate the role of PTX in reducing AKI in patients undergoing CABG by using UNGAL. Although we could not demonstrate a significant difference between the levels of UNGAL of the control and the treatment group, surprisingly we showed a significant difference in 24 and 48 hours $\mathrm{sCr}$.

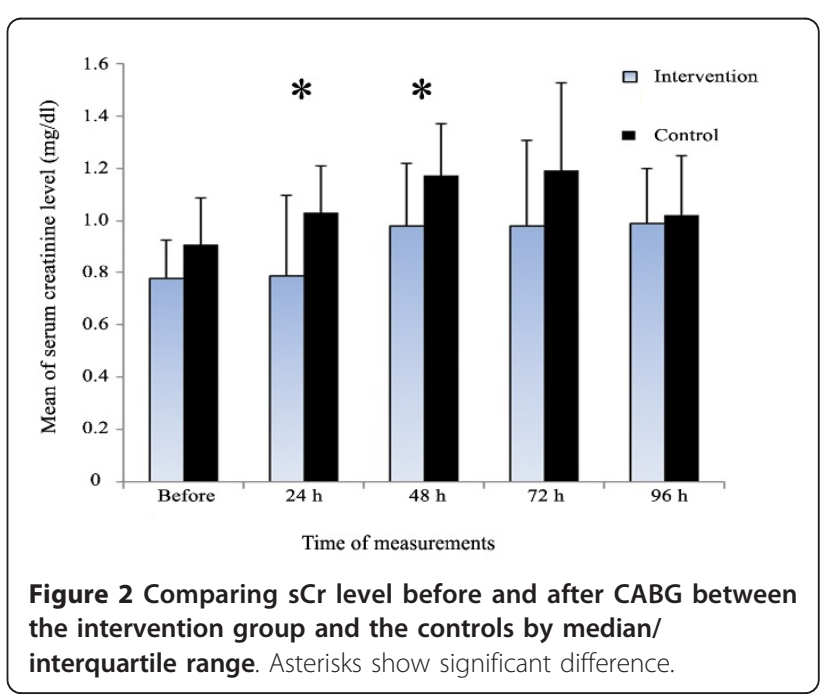


Table 2 Intra- and post operative variables

\begin{tabular}{|c|c|c|c|}
\hline Variable & Intervention $(n=14)$ & Control $(n=14)$ & P-value* \\
\hline \multicolumn{4}{|l|}{ Intraoperative } \\
\hline Infused serum volume (cc) & $1339.29 \pm 203.97$ & $1389.29 \pm 284.32$ & 0.59 \\
\hline $\mathrm{CVP}^{3}\left(\mathrm{~cm} \mathrm{H}_{2} \mathrm{O}\right)$ & $9.50 \pm 2.76$ & $7.71 \pm 2.12$ & 0.67 \\
\hline Urine volume (cc) & $1100.00 \pm 427.42$ & $1400.00 \pm 514.408$ & 0.10 \\
\hline Pump time (Minutes) & $63.21 \pm 23.69$ & $71.50 \pm 20.71$ & 0.33 \\
\hline Aortic Clamp time (Min.) & $37.36 \pm 14.47$ & $42.36 \pm 16.14$ & 0.39 \\
\hline Number of Grafts & $3.14 \pm 1.17$ & $3.36 \pm 0.75$ & 0.56 \\
\hline Use of inotropic drugs (No. of patients) & 2 & 5 & 0.32 \\
\hline \multicolumn{4}{|l|}{ Postoperative } \\
\hline 24-h CVP & $9.68 \pm 1.91$ & $10.29 \pm 3.09$ & 0.53 \\
\hline 24-h mean ABP & $73.09 \pm 21.97$ & $80.00 \pm 5.99$ & 0.26 \\
\hline 24-h urine volume (cc) & $3864.29 \pm 855.39$ & $3693.93 \pm 651.96$ & 0.55 \\
\hline Bleeding (3 hours)(cc) & $96.43 \pm 88.71$ & $139.29 \pm 122.75$ & 0.29 \\
\hline 24-h bleeding (cc) & $485.71 \pm 200.41$ & $500.00 \pm 180.81$ & 0.84 \\
\hline 24-h sCr level (mg/dl) & $0.79 \pm 0.18$ & $1.03 \pm 0.43$ & 0.02 \\
\hline 48-h sCr level (mg/dl) & $0.98 \pm 0.20$ & $1.17 \pm 0.24$ & 0.03 \\
\hline 72-h sCr level (mg/dl) & $1.04 \pm 0.32$ & $0.96 \pm 0.24$ & 0.46 \\
\hline 96-h sCr level (mg/dl) & $1.02 \pm 0.23$ & $0.99 \pm 0.21$ & 0.69 \\
\hline CRP after $24 \mathrm{~h}$ & $11.27 \pm 3.83$ & $12.16 \pm 4.18$ & 0.56 \\
\hline 3-h UNGAL level (ng/ml) & $11.07 \pm 8.63$ & $15.50 \pm 10.60$ & 0.23 \\
\hline 24-h UNGAL level (ng/ml) & $23.64 \pm 15.74$ & $26.86 \pm 18.97$ & 0.11 \\
\hline Mechanical ventilation time (h) & $6.91 \pm 2.30$ & $8.16 \pm 3.61$ & 0.28 \\
\hline Length of ICU stay (h) & $43.75 \pm 30.89$ & $41.60 \pm 31.46$ & 0.63 \\
\hline TNG dosage $(\mathrm{mg})$ & $0.31 \pm 0.06$ & $0.28 \pm 0.02$ & 0.19 \\
\hline \multirow[t]{2}{*}{ Heparin (IU/24 h) } & 26035.71 & \pm 28714.29 & \pm 0.14 \\
\hline & 4343.27 & 4983.48 & \\
\hline
\end{tabular}

* $P$ values $<0.05$ were considered as significant.

NGAL is a marker of injury, while creatinine is a marker of function and the expected effect would be increase of UNGAL rather than $\mathrm{sCr}$. One explanation may be the size of the sample, which may be insufficient in this case.

AKI is a serious complication after cardiac surgery that occurs in $30 \%$ to $50 \%$ of all cardiac surgical patients which increases mortality and morbidity and therefore, hospital stay duration [2,3]. Patients with AKI had an eightfold increase in 30-day mortality [12].

In our study, the incidence of AKI was similar to other studies ( $42 \%$ after 48 hours). However, patients with a history of previous renal failure were excluded and enrolled patients had a good physiological and health condition (Euroscore 2). Thus, it seems that the real incidence of AKI among patients who undergo CABG is much higher.

Measuring urine or plasma NGAL of patients in the first hours after $\mathrm{CPB}$ in predicting subsequent renal injury is debatable. One study showed that measuring UNGAL level 2 hours after pediatric cardiac surgery can predict AKI with $100 \%$ sensitivity and $98 \%$ specificity. Other studies showed limited diagnostic accuracy in predicting AKI defined by change in serum creatinine after cardiac surgery $[4,8,13]$. A recent study on 50 patients with $\mathrm{CPB}$ showed a rapid incline in the postoperative UNGAL level, significantly correlated with AKI [14]. We used this biomarker as a rapid detector of AKI and surveyed the effect of PTX but could not find a strong correlation between $3 \mathrm{~h}$ and $12 \mathrm{~h}$ UNGAL measurements with $24 \mathrm{~h}$ and $48 \mathrm{~h}$ sCr levels.

Most Patients undergoing cardiac surgical procedures with CPB have SIRS [15-17] The antioxidant and antiinflammatory effects of PTX have been showed in many studies $[18,19]$. PTX has also been reported to exhibit anticoagulation properties by improving red blood cell deformability, decreasing red blood cell aggregation, and inhibiting neutrophil adhesion [20].

The effect of PTX in alleviating the inflammatory process after cardiac surgery has been studied in few randomized controlled studies. Based on their results, patients receiving PTX had lower levels of inflammatory factors 
and reduced duration of ventilation and better outcome $[21,22]$. In one study, administrating PTX to elderly CABG surgical patients (age $>80$ ) showed a significantly less rise of inflammatory factors such as PMN elastase, CRP, IL-6, IL-8 and IL-10 [21].

In another randomized clinical trial, effect of PTX on reducing the inflammatory effect following $\mathrm{CPB}$ surgery in 60 patients was studied by administrating either IV infusion of PTX during surgery or normal saline as placebo. Measurements of inflammatory factors (i.e., white blood cell count and differentiation, C-reactive protein, TNF- $\alpha$ and -6 ) at 6 and 24 hoursIL postoperatively showed a significant reduction in the intervention group compared to the control group [23]. In our study we could not demonstrate significant effect of PTX on CRP in the first 24 hours after surgery.

To our knowledge, this is the first published study that assesses the effect of PTX on preventing AKI by measuring UNGAL. We expected PTX to have a significant effect on reducing UNGAL regarding its anti-inflammatory and antioxidant effects in early postoperative period. However, we could not find such a correlation. This might be due to the small size of our study population, tough we must note the weak correlation of NGAL with $\mathrm{sCr}$ in our study.

Serum Creatinine is still a standard method for evaluating renal function. The effect of PTX in reducing renal injury by measuring $\mathrm{sCr}$ and a-1-microglobulin was investigated in one study and a beneficial role of PTX on prevention of kidney injury was observed [11]. Our study, confirms this effect of PTX by preventing rise of $\mathrm{sCr}$ at 24 and 48 hours. This may be related to other than the anti-inflammatory and antioxidant properties of PTX. We followed-up the changes in the $\mathrm{sCr}$ in 72 and 96 hours postoperatively and did not observe any significant change in these measurements.

We also could not find a significant effect of PTX on early outcomes such as intubation time and the duration of ICU stay as other studies claimed [22]. Again, we contribute this to small sample size.

PTX may lead to abdominal discomfort with nausea and vomiting and also has vasodilatory effect that may increase post operative bleeding [24]. There was no difference between the groups regarding homodynamic parameters or bleeding volume. This is an important finding because PTX is not desirably used in cardiac patients due to the fear from hemorrhage.

\section{Study limitations}

The main limitation of our study is the small number of patients enrolled, which have led to a relatively low study power in finding significant differences between the two study groups. The other limitation is that the UNGAL measurement is less frequent than similar studies. We also measured CRP as an inflammatory indicator, and did not measure changes of inflammatory cytokines that may show the acute anti-inflammatory and antioxidant effects of PTX better than CRP.

\section{Conclusion}

In this study, we show that UNGAL has a weak correlation with $\mathrm{sCr}$ after cardiac surgery. PTX reduces the rise of UNGAL although not significantly. PTX may have some effect on preventing AKI as determined by attenuation of creatinine rise. In our study, PTX did not increase the risk of bleeding and caused no hemodynamic instability. We suggest future larger studies to show the effect of PTX to prevent end organ damages such as AKI after cardiopulmonary bypass. More clinical trials are needed to fully determine the different aspects of administrating PTX such as standard doses, duration of infusion and its long-term effect on mortality and morbidity.

\section{Key messages}

- Acute kidney injury (AKI) is a common complication after coronary artery bypass graft.

- Pentoxifylline tends to reduce UNGAL although not significant.

- Pentoxifylline can prevent AKI after cardiac surgery as detected by serum creatinine.

\section{Abbreviations}

AKI: Acute Kidney Injury; AKIN: Acute Kidney Injury Network; ALT: Alanine Aminotransferase; AST: Aspartate Aminotransferase; CABG: Coronary Artery Bypass Graft; CPB: Cardiopulmonary bypass; CRP: C-reactive protein; IL: Interleukin; IV: Intravenous; PTX: Pentoxifylline; sCr: Serum Creatinine Concentration; SD: Standard Deviation; SIRS: Systemic Inflammatory Response Syndrome; TNF: Tumor Necrosis Factor; UNGAL: Urinary Neutrophil Gelatinase-Associated Lipocalin; XO: Xanthine oxidase:

\section{Acknowledgements}

This study was funded by the Tehran Heart Center, Tehran University of Medical Sciences. The authors would like to thank Dr. Mahmood Sheikh Fathollahi and Dr. Mohammad Reza Boroumand for their help.

\section{Author details}

${ }^{1}$ Department of Anesthesiology and Critical Care, Tehran Heart Center, Tehran University of Medical Sciences, Tehran, Iran. ${ }^{2}$ Department of Cardiovascular Surgery, Tehran Heart Center, Tehran University of Medical Sciences, Tehran, Iran. '3eiden Academy on Vitality and Ageing, Leiden, the Netherlands. ${ }^{4}$ Department of Nephrology, Tehran Heart Center, Tehran University of Medical Sciences, Tehran, Iran. ${ }^{5}$ Department of Cardiothoracic Surgery and Anesthesia, Barts and the London NHS Trust, St Bartholomew's Hospital, London, UK.

\section{Authors' contributions}

$\mathrm{KB}$ gave the conception, revised the draft and gave the final approval. AK has performed cardiac operations and acted as surgical consultant, did final scientific revision and gave final approval. AS has performed literature review, data analysis, drafting and final edition. HS has induction of Anesthesia, revised the draft and gave final approval. MK has performed as Nephrological consultant, did scientific revision and gave final approval. KA has performed cardiac operations and acted as surgical consultant, did final scientific revision and gave final approval. FY performed as Methodological 
consultant, did scientific revision and gave final approval. BH performed as Methodological consultant, did scientific revision and gave final approval. VB did the final language edit and gave final approval.

\section{Competing interests}

The authors declare that they have no competing interests.

Received: 28 June 2010 Accepted: 19 January 2011

Published: 19 January 2011

\section{References}

1. Mehta RL, Kellum JA, Shah SV, Molitoris BA, Ronco C, Warnock DG, Levin A: Acute Kidney Injury Network: Report of an initiative to improve outcomes in acute kidney injury. Crit Care 2007, 11:R31.

2. Haase M, Haase-Fielitz A, Bagshaw SM, Ronco C, Bellomo R: Cardiopulmonary bypass-associated acute kidney injury: a pigment nephropathy? Contrib Nephrol 2007, 156:340-353.

3. Rosner MH, Okusa MD: Acute kidney injury associated with cardiac surgery. Clin J Am Soc Nephrol 2006, 1:19-32.

4. Mishra J, Dent C, Tarabishi R, Mitsnefes MM, Ma Q, Kelly C, Ruff SM, Zahedi K, Shao M, Bean J, Mori K, Barasch J, Devarajan P: Neutrophil gelatinase-associated lipocalin (NGAL) as a biomarker for acute renal injury after cardiac surgery. Lancet 2005, 365:1231-8.

5. Visser J, Groen H, Klatter F, Rozing J: Timing of pentoxifylline treatment determines its protective effect on diabetes development in the Bio Breeding rat. Eur J Pharmacol 2002, 445:133-40.

6. Sullivan GW, Carper HT, Novick WJ Jr, Mandell GL: Inhibition of the inflammatory action of interleukin-1 and tumor necrosis factor (alpha) on neutrophil function by pentoxifylline. Infect Immun 1988, 56:1722-9.

7. Hammerman C, Goldschmidt D, Caplan MS, Kaplan M, Schimmel MS, Eidelman Al, Branski D, Hochman A: Amelioration of ischemia-reperfusion injury in rat intestine by pentoxifylline-mediated inhibition of xanthine oxidase. J Pediatr Gastroenterol Nutr 1999, 29:69-74.

8. Wu HM, Yuan QY, Zhou RL, Li J, Liu GJ: Pentoxifylline for diabetic kidney disease (Protocol). Cochrane Database of Systematic Reviews 2007, , 4: CD006800.

9. Okumura AS, Rodrigues LE, Martinelli R: Pentoxifylline in ischemia-induced acute kidney injury in rats. Ren Fail 2009, 31:829-32.

10. Groesdonk HV, Bauer A, Kreft B, Heringlake M, Paarmann H, Pagel H: Urodilatin and pentoxifylline prevent the early onset of Escherichia coliinduced acute renal failure in a model of isolated perfused rat kidney. Kidney Blood Press Res 2009, 32:81-90.

11. Boldt J, Brosch C, Piper SN, Suttner S, Lehmann A, Werling C: Influence of prophylactic use of pentoxifylline on postoperative organ function in elderly cardiac surgery patients. Crit Care Med 2001, 29:952-8.

12. Kheterpal S, Tremper KK, Heung M, Rosenberg AL, Englesbe M, Shanks AM, Campbell DA: Development and validation of an acute kidney injury risk index for patients undergoing general surgery: results from a national data set. Anesthesiology 2009, 110:505-15.

13. Wagener G, Gubitosa G, Wang S, Borregaard N, Kim M, Lee HT: Urinary Neutrophil Gelatinase-Associated Lipocalin and Acute Kidney Injury After Cardiac Surgery. Am J Kidney Dis 2008, 52:425-33.

14. Tuladhar SM, Püntmann VO, Soni M, Punjabi PP, Bogle RG: Rapid detection of acute kidney injury by plasma and urinary neutrophil gelatinaseassociated lipocalin after cardiopulmonary bypass. J Cardiovasc Pharmacol 2009, 53:261-6.

15. Asimakopoulos $\mathrm{G}$, Gourlay T: A review of anti-inflammatory strategies in cardiac surgery. Perfusion 2003, 18:7-12.

16. Chong AJ, Hampton CR, Verrier ED: Microvascular Inflammatory Response in Cardiac Surgery Seminars in Cardiothoracic and Vascular. Anesthesia 2003, 7:333-54.

17. Laffey JG, Boylan JF, Cheng DC: The systemic inflammatory response to cardiac surgery: implications for the anesthesiologist. Anesthesiology 2002, 97:215-52.

18. Radfar M, Larijani B, Hadjibabaie M, Rajabipour B, Mojtahedi A, Abdollahi M: Effects of pentoxifylline on oxidative stress and levels of EGF and NO in blood of diabetic type-2 patients; a randomized, double-blind placebocontrolled clinical trial. Biomed Pharmacother 2005, 59:302-6.

19. Zhang M, Xu YJ, Saini HK, Turan B, Liu PP, Dhalla NS: Pentoxifylline attenuates cardiac dysfunction and reduces TNF-alpha level in ischemicreperfused heart. Am J Physiol Heart Circ Physio 2005, 289:H832-9.
20. Chapelier A, Reignier J, Mazmanian M, Detruit H, Dartevelle P, Parquin F, Cerrina J, Le Roy Ladurie F, Hervé P: Pentoxifylline and lung ischemiareperfusion injury: application to lung transplantation. Université ParisSud Lung Transplant Group. J Cardiovasc Pharmacol 1995, 25(Suppl 2): S130-3.

21. Boldt J, Brosch C, Lehmann A, Haisch G, Lang J, Isgro F: Prophylactic use of pentoxifylline on inflammation in elderly cardiac surgery patients. Ann Thorac Surg 2001, 71:1524-9.

22. Heinze H, Rosemann C, Weber C, Heinrichs G, Bahlmann L, Misfeld M, Heringlake $M$, Eichler W: A single prophylactic dose of pentoxifylline reduces high dependency unit time in cardiac surgery - a prospective randomized and controlled study. Eur J Cardiothorac Surg 2007, 32:83-9.

23. Cağ li K, Ulaș MM, Ozișik K, Kale A, Bakuy V, Emir M, Balci M, Topbaș M, Sener $E$, Tassdemir $O$ : The intraoperative effect of pentoxifylline on the inflammatory process and leukocytes in cardiac surgery patients undergoing cardiopulmonary bypass. Perfusion 2005, 20:45-51.

24. Hemmer CJ, Hort G, Chiwakata CB, Seitz R, Egbring R, Gaus W, Hogel J, Hassemer M, Nawroth PP, Kern P, Dietrich M: Supportive pentoxifylline in falciparum malaria: no effect on tumor necrosis factor alpha levels or clinical outcome: a prospective, randomized, placebo-controlled study. Am J Trop Med Hyg 1997, 56:397-403.

doi:10.1186/1749-8090-6-8

Cite this article as: Barkhordari et al:: Effect of pentoxifylline on preventing acute kidney injury after cardiac surgery by measuring urinary neutrophil gelatinase - associated lipocalin. Journal of Cardiothoracic Surgery 2011 6:8.

\section{Submit your next manuscript to BioMed Central and take full advantage of:}

- Convenient online submission

- Thorough peer review

- No space constraints or color figure charges

- Immediate publication on acceptance

- Inclusion in PubMed, CAS, Scopus and Google Scholar

- Research which is freely available for redistribution

Submit your manuscript at www.biomedcentral.com/submit
C Biomed Central 